Special issue in honor of Prof. H.K. Lichtenthaler

\title{
In honor of Hartmut Karl Lichtenthaler
}

\author{
G. GOVINDJEE
}

Department of Plant Biology, Department of Biochemistry and Center of Biophysics \& Quantitative Biology, University of Illinois at Urbana-Champaign, Urbana, IL 61801, USA

\begin{abstract}
We honor here Hartmut Karl Lichtenthaler, a pioneer of plant physiology, plant biochemistry, plant biophysics, plant molecular biology, and stress physiology. His contributions to the ingenious use of chlorophyll $a$ fluorescence imaging in understanding the physiological processes in leaves stand out. We wish him many happy and productive years of research and educating others.
\end{abstract}

Keywords: chlorophyll fluorescence imaging; Eugene Rabinowitch; isoprenoid biosynthesis; Melvin Calvin; phylloquinone; Robert Emerson.

I express my heartfelt greetings, and best wishes, for many happy and productive years to my dear friend Hartmut Lichtenthaler at the University of Karlsruhe, Germany, whom I consider as my younger brother. A quick look at the 'photosynthesis literature', tells us that the name Hartmut Lichtenthaler is not only synonymous with the discovery of phylloquinone in Photosystem I, but brings, before our eyes, the images of osmiophilic plastoglobules (see Lichtenthaler 2013, for a review), and the intricate differences in ultrastructure, pigment composition and photosynthetic rates of 'sun chloroplasts' $v s$. 'shade chloroplasts' from sun and shade leaves (see a review by Lichtenthaler and Babani 2004), as well as the processes that led to the forest decline (see Sharkey and Govindjee 2016). In addition, Hartmut is well known for detecting and establishing, in close cooperation with the chemist Michel Rohmer, the non-mevalonate desoxyxylulosephosphate (DOXP)/methylerythritol phosphate (MEP) pathway of isoprenoid biosynthesis in chloroplasts, which is responsible for the biosynthesis of carotenoids, plastoquinone-9, phylloquinone, isoprene, and phytol, that are essential components of the photosynthetic apparatus (Lichtenthaler et al. 1997, Lichtenthaler 1999).

Furthermore, and closer to my heart is Hartmut's authoritative research on the use of 'chlorophyll (Chl) $a$ fluorescence' (Govindjee et al. 1986, Lichtenthaler 1988, Papageorgiou and Govindjee 2004) in studying the effects of stress on plants (see Lichtenthaler and Rinderle 1988, Lichtenthaler et al. 1998). In fact, Hartmut is the top authority on the use of $\mathrm{Chl}$ fluorescence in plants under stress (see his own account: Lichtenthaler 2020).

Moreover, Hartmut is the pioneer of imaging the red and far-red Chl $a$ fluorescence of whole leaves (Lang et al. 1994, Lichtenthaler and Miehé 1997, Buschmann and Lichtenthaler 1998) and in the application of Chl fluorescence imaging (at the maximum $\mathrm{F}_{\mathrm{m}}$, and the steady-state $F_{\mathrm{s}}$ after 5 min of saturating light) in order to simultaneously determine, in a nondestructive way, the individual photosynthetic activity of several thousand or ten thousand leaf pixels and the gradients in photosynthetic rates over the leaf surface (Lichtenthaler and Babani 2000, Lichtenthaler et al. 2000, 2007, 2013). No one can match the description of research what Hartmut has done better than what he himself has written in an outstanding review (see Lichtenthaler 2015). To show my connection with Hartmut's Chl $a$ fluorescence imaging, I refer the readers to my efforts, with the late Robert (Bob) Clegg (1945-2012) on the imaging of lifetime of $\mathrm{Chl} a$ fluorescence (see e.g.,

Received 18 November 2020

Accepted 19 November 2020

Published online 17 December 2020

e-mail: gov@illinois.edu

Acknowledgment: I thank Roland Valcke for his invitation to participate in this special honor to Professor Hartmut K. Lichtenthaler (also see footnote for websites on Hartmut ${ }^{*}$ ), and Rajni Govindjee for the photograph.

"Wikipedia:https://en.wikipedia.org/wiki/Hartmut_K._Lichtenthaler; biography:https://peoplepill.com/people/hartmut-k-lichtenthaler/; curriculum vitae: https://www.botanik.kit.edu/molbio/1008.php; scientific publications: https://www.botanik.kit.edu/molbio/1003.php. Conflict of interest: The author declares no conflict of interest. 
Holub et al. 2000, 2007).

Hartmut continues to amaze me with not only his research, but his contributions to writing tributes remembering the discoverers of the photosynthetic carbon fixation cycle (see Lichtenthaler et al. 2015, Buchanan et al. 2016, for Andrew A. Benson; and Govindjee et al. 2020 for Melvin Calvin). On top of all this, he has provided for the future generation, English translation of Robert Emerson's $1927 \mathrm{PhD}$ thesis (Emerson 1927), in German, under Otto H. Warburg (see Lichtenthaler and Björn 2020, for a prelude, see Govindjee 2020).

I end this article on Hartmut Lichtenthaler's outstanding and exciting contributions to photosynthesis by showing a photograph of two of us (Fig. 1) paying homage to two pioneers of the past: Robert Emerson (1903-1959; Govindjee 2020), and Eugene Rabinowitch (1901-1973; Govindjee et al. 2019).

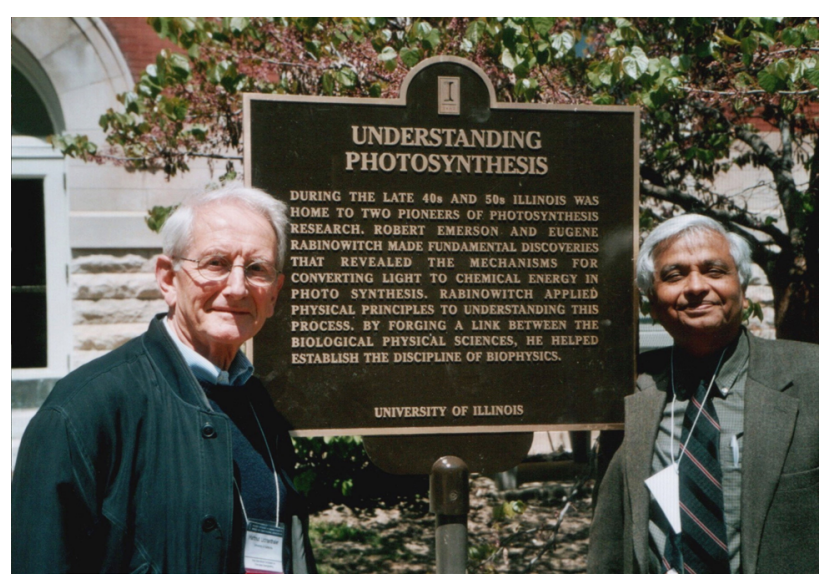

Fig. 1. A photograph of Hartmut Lichtenthaler (left) and the author Govindjee (right), who have continuously exploited the use of Chl $a$ fluorescence in understanding photosynthesis and the life of plants. They are shown here at the historical plaque, which honors two pioneers of photosynthesis research - Robert Emerson and Eugene Rabinowitch - who had their laboratories in the Natural History Building (in the background), in Urbana, Illinois, USA. This photo was taken in May 2005 during the 'International Symposium on Chloroplast Engineering', held at the University of Illinois at Urbana-Champaign. Source: Rajni Govindjee.

\section{References}

Buchanan B.B., Douce R., Govindjee G. et al.: Andrew Alm Benson, 1917-2015. Biographical Memoirs. Pp. 16. National Academy of Sciences, USA 2016.

Buschmann C., Lichtenthaler H.K.: Principles and characteristics of multi-colour fluorescence imaging of plants. - J. Plant Physiol. 152: 297-314, 1998.

Emerson R.: Über die Wirkung von Blausäure, Schwefelwasserstoff und Kohlenoxyd auf die Atmung verschiedener Algen. Pp. 32. Friedrich-Wilhelms-Universität zu Berlin, 1927. [In German]

Govindjee G.: Robert Emerson, a major contributor to photosynthesis, had pioneered research in respiration in the 1920s, under Otto Warburg. - J. Plant Sci. Res. 36: 1-4, 2020.

Govindjee G., Amesz J., Fork D.C. (ed.): Light Emission by
Plants and Bacteria. Pp. 660. Academic Press, Orlando 1986. Govindjee G., Nonomura A., Lichtenthaler H.K.: Remembering Melvin Calvin (1911-1997), a highly versatile scientist of the 20th century. - Photosynth. Res. 143: 1-11, 2020.

Govindjee G., Papageorgiou G.C., Govindjee R.: Eugene I. Rabinowitch: A prophet of photosynthesis and of peace in the world. - Photosynth. Res. 141: 143-150, 2019.

Holub O., Seufferheld M.J., Gohlke C. et al.: Fluorescence lifetime imaging (FLI) - a new technique in photosynthesis research. - Photosynthetica 38: 581-599, 2000.

Holub O., Seufferheld M.J., Gohlke C. et al.: Fluorescence lifetime imaging microscopy of Chlamydomonas reinhardtii: Non-photochemical quenching mutants and the effect of photosynthetic inhibitors on the slow chlorophyll fluorescence transient. - J. Microsc. 226: 90-120, 2007.

Lang M., Lichtenthaler H.K., Sowinska M. et al.: Blue, green and red fluorescence signatures and images of tobacco leaves. - Bot. Acta 107: 230-236, 1994.

Lichtenthaler H.K. (ed.): Applications of Chlorophyll Fluorescence in Photosynthesis Research, Stress Physiology, Hydrobiology and Remote Sensing. Pp. 366. Springer, Dordrecht 1988

Lichtenthaler H.K.: The 1-deoxy-D-xylulose-5-phosphate pathway of isoprenoid biosynthesis in plants. - Annu. Rev. Plant Phys. 50: 47-65, 1999.

Lichtenthaler H.K.: Plastoglobuli, thylakoids, chloroplast structure and development of plastids. - In: Biswal B., Krupinska K., Biswal U.C. (ed.): Plastid Development in Leaves During Growth and Senescence. Advances in Photosynthesis and Respiration. Vol. 36. Pp. 337-361. Springer, Dordrecht 2013.

Lichtenthaler H.K.: Fifty-five years of research on photosynthesis, chloroplasts, and stress physiology of plants: 1958-2013. In: Lüttge U., Beyschlag W (ed.): Progress in Botany. Vol. 76. Pp. 3-42. Springer, Cham 2015.

Lichtenthaler H.K.: My contact and cooperation with Govindjee over the last five decades: Chlorophyll fluorescence and Rebeiz Foundation. - Photosynthetica 58: 976-983, 2020.

Lichtenthaler H.K., Babani F.: Detection of photosynthetic activity and water stress by imaging the red chlorophyll fluorescence. - Plant Physiol. Bioch. 38: 889-895, 2000.

Lichtenthaler H.K., Babani F.: Light adaption and senescence of the photosynthetic apparatus: changes in pigment composition, chlorophyll fluorescence parameters and photosynthetic activity during light adaptation and senescence of leaves. In: Papageorgiou G.C., Govindjee G. (ed.): Chlorophyll a Fluorescence: A Signature of Photosynthesis. Pp. 713-736. Springer, Dordrecht 2004.

Lichtenthaler H.K., Babani F., Langsdorf G.: Chlorophyll fluorescence imaging of photosynthetic activity in sun and shade leaves of trees. - Photosynth. Res. 93: 235-244, 2007.

Lichtenthaler H.K., Babani F., Langsdorf G., Buschmann C.: Measurement of differences in red chlorophyll fluorescence and photosynthetic activity between sun and shade leaves by fluorescence imaging. - Photosynthetica 38: 521-529, 2000.

Lichtenthaler H.K., Björn L.O.: English translation of the 1927 doctoral thesis (in German) of Robert Emerson, a pioneer in Photosynthesis. - J. Plant Sci. Res. 36: 5-24, 2020.

Lichtenthaler H.K., Buchanan B.B., Douce R., Govindjee G.: Andrew A. Benson, 1917-2015. - Photosynth. Res. 124: 131$135,2015$.

Lichtenthaler H.K., Langsdorf G., Buschmann C.: Uptake of diuron and concomitant loss of photosynthetic activity in leaves as visualized by imaging the red chlorophyll fluorescence. - Photosynth. Res. 116: 355-361, 2013.

Lichtenthaler H.K., Miehé J.A.: Fluorescence imaging as a 
diagnostic tool for plant stress. - Trends Plant Sci. 2: 316$320,1997$.

Lichtenthaler H.K., Rinderle U.: The role of chlorophyll fluorescence in the detection of stress conditions in plants. Crit. Rev. Anal. Chem. 19: S29-S85, 1988.

Lichtenthaler H.K., Rohmer M., Schwender J.: Two independent bio-chemical pathways for isopentenyl diphosphate (IPP) and isoprenoid biosynthesis in higher plants. - Physiol. Plantarum 101: 643-652, 1997.

Lichtenthaler H.K., Wenzel O., Buschmann C., Gitelson A.:
Plant stress detection by reflectance and fluorescence. - Ann. NY Acad. Sci. 851: 271-285, 1998.

Papageorgiou G.C., Govindjee G. (ed.): Chlorophyll a Fluorescence: A Signature of Photosynthesis. Advances in Photosynthesis and Respiration. Vol. 19. Pp. 818. Springer, Dordrecht 2004.

Sharkey T.D., Govindjee G.: Hartmut Lichtenthaler: an authority on chloroplast structure and isoprenoid biochemistry. Photosynth. Res. 128: 117-123, 2016.

(C) The authors. This is an open access article distributed under the terms of the Creative Commons BY-NC-ND Licence. 